\title{
A framework of integrated hydrological and hydrodynamic models using synthetic rainfall for flash flood hazard mapping of ungauged catchments in tropical zones
}

\author{
Worapong Lohpaisankrit ${ }^{1}$, Günter Meon ${ }^{1}$, and Tawatchai Tingsanchali ${ }^{2}$ \\ ${ }^{1}$ Department of Hydrology, Water Management and Water Protection, University of Braunschweig, \\ Braunschweig, 38106, Germany \\ ${ }^{2}$ School of Engineering and Technology, Asian Institute of Technology, Pathumthani, 12120, Thailand
}

Correspondence to: Worapong Lohpaisankrit (w.lohpaisankrit@gmail.com)

Published: 12 May 2016

\begin{abstract}
Flash flood hazard maps provide a scientific support to mitigate flash flood risk. The present study develops a practical framework with the help of integrated hydrological and hydrodynamic modelling in order to estimate the potential flash floods. We selected a small pilot catchment which has already suffered from flash floods in the past. This catchment is located in the Nan River basin, northern Thailand. Reliable meteorological and hydrometric data are missing in the catchment. Consequently, the entire upper basin of the main river was modelled with the help of the hydrological modelling system PANTA RHEI. In this basin, three monitoring stations are located along the main river. PANTA RHEI was calibrated and validated with the extreme flood events in June 2011 and July 2008, respectively. The results show a good agreement with the observed discharge data. In order to create potential flash flood scenarios, synthetic rainfall series were derived from temporal rainfall patterns based on the radar-rainfall observation and different rainfall depths from regional rainfall frequency analysis. The temporal rainfall patterns were characterized by catchment-averaged rainfall series selected from 13 rainstorms in 2008 and 2011 within the region. For regional rainfall frequency analysis, the well-known L-moments approach and related criteria were used to examine extremely climatic homogeneity of the region. According to the L-moments approach, Generalized Pareto distribution was recognized as the regional frequency distribution. The synthetic rainfall series were fed into the PANTA RHEI model. The simulated results from PANTA RHEI were provided to a 2-D hydrodynamic model (MEADFLOW), and various simulations were performed. Results from the integrated modelling framework are used in the ongoing study to regionalize and map the spatial distribution of flash flood hazards with four levels of flood severities. As an overall outcome, the presented framework can be applied in areas with inadequate runoff records.
\end{abstract}

\section{Introduction}

Flash floods are distinguished from river floods by high flowvelocities and rapid rises of water levels within a short period. Due to their typical characteristics, flash floods are difficult to forecast and usually result in the limitation of time available for warning to be prepared. Thus, they are the most dangerous events (Collier, 2007). Based on statistical analysis of Jonkman and Vrijling (2008), the average mortality for flash floods is highest compared to drainage and river floods. Therefore, flash flood hazard maps are urgent necessity.

Flash flood hazard maps are an essential tool for flood risk mitigation and management. However, flash flood hazard mapping is complicated and faces many uncertainties because flash floods often occur in ungauged basins. Thus, flash flood studies are challenging and still poorly understood for many countries, especially tropical regions. One of the major challenges is the scarcity of reliable runoff data and high 


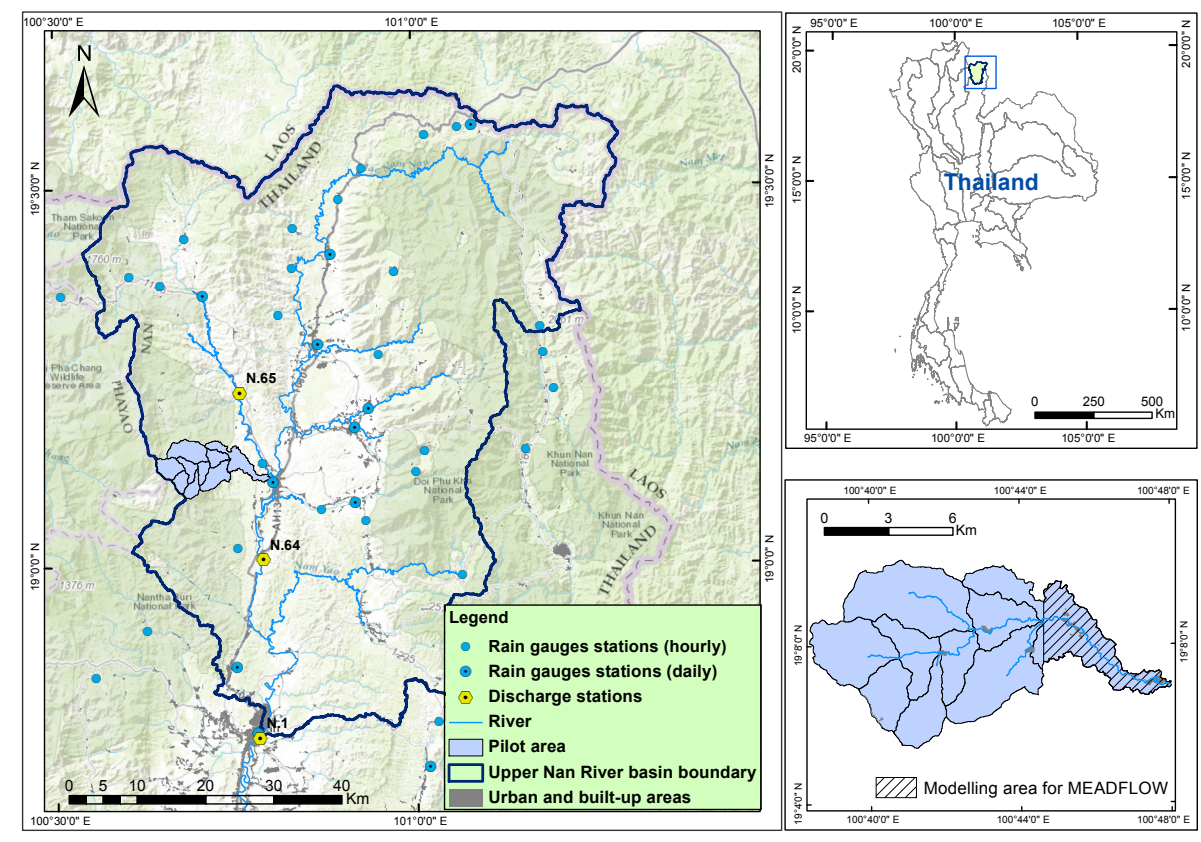

Figure 1. Study area: upper Nan River basin (left), a pilot catchment (right bottom).

resolution rainfall data in both spatial and temporal scales (Marchi et al., 2010). As will be seen, this is one of the main challenges this study aims to solve.

Physically based distributed hydrological models, rainfallrunoff models with high spatial and temporal resolutions, help to understand mechanisms of flash floods. They can be used to deal with the lack of quantitative information in ungauged basins as well. The advantage of the distributed hydrological models is that their input parameters are often related to the physical attributes of the catchments (Ogden et al., 2000). Thus, hydrological models have been applied in flash flood studies by numerous researchers (Rulli and Rosso, 2002; Reed et al., 2007; Braud et al., 2010). Even though many advanced hydrological models are available, the lack of temporal high resolution of rainfall deprives researchers of accurately estimating potential of flash floods.

Sarhadi et al. (2012) mapped floodplains at ungauged rivers based on flood frequency analysis of annual maximum streamflow data and multivariate linear regression models using catchment characteristics. Flood hazard maps were created with the help of a one dimensional hydraulic model; notwithstanding, rainfall which is the most important factor in flash floods was omitted. In contrast to Sarhadi et al. (2012), this study applied regional frequency analysis to rainfall data since flash floods are often triggered by heavy rainfall.

The aim of the present study is to propose a framework for flash flood hazard mapping. We selected a small catchment with $76 \mathrm{~km}^{2}$ as a pilot study area. The innovative aspect of this study is that multidisciplinary approaches were applied:
- Synthetic rainfall series were derived from radar-rainfall observation to estimate flash flood potential.

- Regional rainfall frequency analysis was introduced to test homogeneity of the region.

- Finally, integrated hydrological and hydrodynamic modelling was used to delineate flash flood hazard maps.

\section{Study region and data}

The Nam Rim basin, an ungauged subbasin of the upper Nan River basin, was selected as a pilot catchment covering $76 \mathrm{~km}^{2}$ (Fig. 1). The Nam Rim stream flows directly into the main river of the Nan River. Elevations in the catchment range from $1455 \mathrm{~m}$ to $222 \mathrm{~m}$ a.m.s.l. The mean catchment slope is $38 \%$. In this catchment, flash floods which include debris flow and mudslides have caused flooding on agricultural lands and settlement areas, as seen for example during tropical depression Haima in 2011 (DMR, 2011).

Rainfall data recorded every $24 \mathrm{~h}$ with a standard rain gauge. The rainfall data is available from 1993 to 2012. Another type of rain gauges automatically measures rainfall every $15 \mathrm{~min}$. Since 2006, automatic rain gauges have started to operate. Unfortunately, many of them had been operated for only three or four years and contained too few heavy rainfall events for statistical analysis. Other important meteorological data, namely, wind speed, sunshine duration and temperature, were obtained for the purpose of hydrological modelling. In addition, Radar-rainfall observations are available 


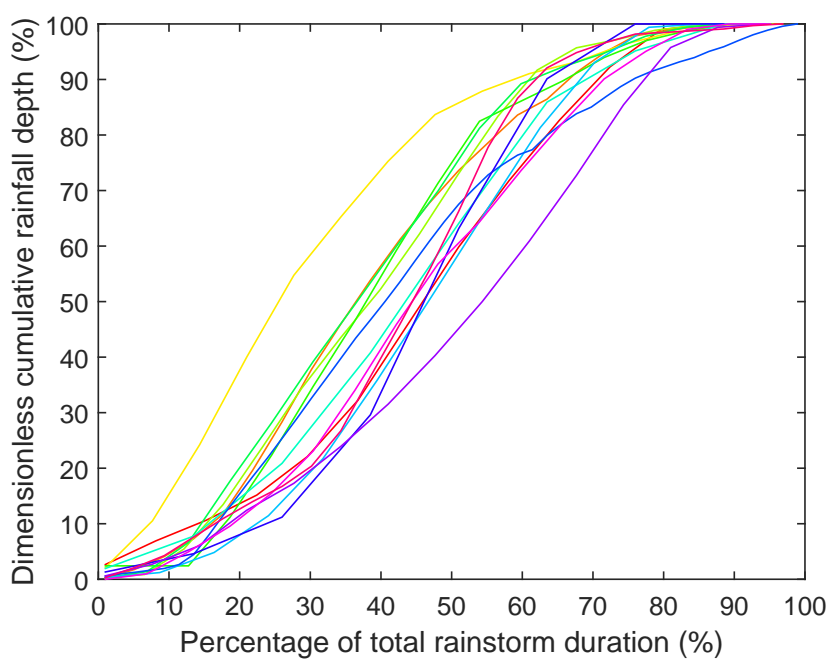

Figure 2. Dimensionless mass curve of 13 rainstorms selected in June, July and August of 2008 and 2011.

for this study area. The radar station with a $240 \mathrm{~km}$ observation range covering the study area is located at Chiang Rai $\left(19^{\circ} 57^{\prime} 41^{\prime \prime} \mathrm{N}, 99^{\circ} 52^{\prime} 53^{\prime \prime} \mathrm{E}\right)$.

In addition to the temporal data required for integrated hydrological and hydrodynamic modelling, spatial data are essential. The spatial data available for this study are digital elevation model (DEM) with $10 \mathrm{~m}$ resolution, and land use and soil maps at $1: 25000$.

\section{Methodology}

\subsection{Development of synthetic rainfall series}

The development of synthetic rainfall series comprises two main procedures: temporal rainfall patterns and regional frequency analysis.

The analysis of temporal rainfall patterns was based on radar-rainfall observations. Radar-rainfall images are available every one hour. The temporal patterns of rainfall were characterized by catchment-averaged rainfall series selected from 13 rainstorms of different rainfall durations in June, July and August of 2008 and 2011. In this study, the temporal patterns of rainfall were described in terms of a dimensionless mass curve. The dimensionless mass curve is a plot between dimensionless cumulative rainfall depth and percentage of total rainstorm duration (Fig. 2). To select the representative temporal pattern of rainfall for this region, the 13 temporal patterns of rainfall were averaged.

Regional frequency analysis (RFA) has become necessary when high-resolution rainfall time series are too short for analysis. Thus, annual maximum $24 \mathrm{~h}(\mathrm{AM} 24 \mathrm{H})$ rainfall data at 11 rain gauge stations were selected to construct the frequency characteristics of the region. The AM24H rainfall data at each station were screened by Grubbs's test (Grubbs, 1969) for outliers. The outliers which depart significantly from the remaining data were excluded from the analysis because they may distort the statistical properties of data (Chow et al., 1988). In order to test the homogeneity of the selected rain gauges and choose the regional distribution function, Lmoment techniques such as discordance and heterogeneity measures were applied (Hosking and Wallis, 1997).

As a result of the previous described steps, synthetic rainfall series are the combination of the temporal rainfall pattern and distribution functions. These rainfall series are a key input for hydrological modelling in order to estimate potential flash floods.

\subsection{Hydrological modelling}

The objective of the hydrological modelling in this study is to estimate runoff in ungauged basins. The upper Nan River basin was modelled by using PANTA RHEI. The physically based PANTA RHEI model is a semi-distributed hydrological modelling system at the watershed scale (Förster et al., 2014). The watershed is divided into subbasins and into hydrological response units (HRUs).

PANTA RHEI is designed with a modular structure which allows users to choose hydrological approaches based on their research objectives and available data. The major hydrological processes of the model include runoff formation, runoff concentration and channel runoff routing.

To improve the model performance, daily rainfall data were disaggregated with hourly rainfall data observed at neighbouring stations and radar-rainfall images.

To calibrate the model, simulated hydrographs from PANTA RHEI were statistically compared with observed hydrographs from the three river discharge stations: N.65, N.64 and N.1 as shown in Fig. 1. The calibrated parameters were carried out to simulate flood hydrographs in the pilot catchment.

\subsection{Flash flood hazard mapping}

MEADFLOW, a 2-D hydrodynamic model, was applied to route simulated discharge from PANTA RHEI and calculate the flood depths and velocities at downstream areas of the pilot catchment as shown in Fig. 1. The MEADFLOW model requires as input data:

- the drainage network extracted from the digital elevation model,

- the Manning-Strickler roughness coefficients which can be estimated from suggested values provided by Chow (1959),

- the upstream and downstream boundaries which were assigned from the simulated discharge and bankfull elevation, respectively.

As mentioned earlier, the pilot catchment is an ungauged catchment. Therefore, maximum flood marks, which oc- 


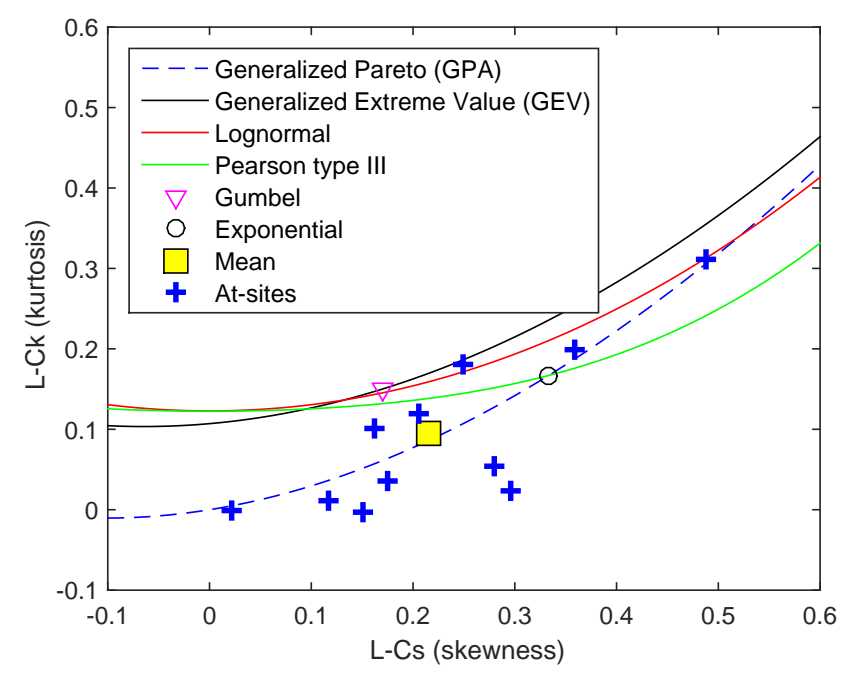

Figure 3. L-moment ratio diagram of 11 rain gauges (at-sites) and regional rainfall data (mean) for selecting the best-fit frequency distribution.

curred in 2011, and information from eyewitness reports were used to approximately calibrate the model.

To produce a flash flood severity grid, DEFRA (2006) determined the flood hazard rating (FHR) based on the combination of flood depths and velocities. The FHR is computed as

$\mathrm{FHR}=D(V+0.5)+\mathrm{DF}$,

where FHR is the flood hazard rating $(-) ; D$ is the depth of flooding (m); $V$ is the flow velocity $\left(\mathrm{m} \mathrm{s}^{-1}\right)$; and DF is the debris factor (-). The debris factor is equal to 1 for $D>0.25 \mathrm{~m}$ and equal to zero otherwise.

\section{Results and discussion}

\subsection{Regional frequency analysis}

Based on the heterogeneity test of the AM24H rainfall data from 11 stations, the region is fairly homogeneous in extremely climatic conditions. The L-moment ratio diagram (Fig. 3) was applied to visually compare the relation of L-Cs and $\mathrm{L}-\mathrm{Ck}$ for the candidate distributions with corresponding relations obtained from the observed rainfall stations (at-site) and the average of the regional data. The square symbol defined by the regional average L-Cs and L-Ck is close to the GPA distribution. Thus, the GPA distribution is identified as the best fit frequency distribution for this region.

\subsection{Hydrological model performance}

In order to characterize the flash floods, PANTA RHEI was tested during short periods of extreme flood events. The extreme flood events triggered the upper Nan River basin in

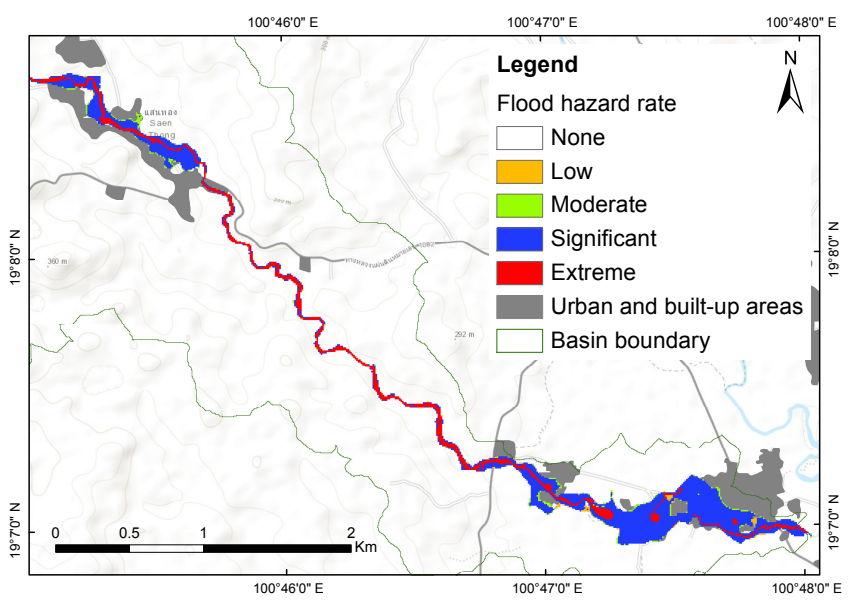

Figure 4. Flood hazard map for downstream areas of the pilot catchment based on the scenario of $15 \operatorname{Tr} 12 \mathrm{H}$.

July-August 2008 and June 2011. Thus, the period of 2529 June 2011 were selected as the calibration period of the model. The validation period was between 17 July and 11 August 2008. The results of the model simulation were evaluated by visual comparison with the observed hydrographs and by the help of statistical indices, namely, efficiency index $(\mathrm{EI})$, coefficient of determination $\left(R^{2}\right)$ and relative peak error (RPE) in Table 1.

According to the analysis of synthetic rainfall series using PANTA RHEI, 15 year return period of rainfall occurring within $12 \mathrm{~h}(15 \operatorname{Tr} 12 \mathrm{H})$ has potential to cause flash floods in the catchment. The simulated flash flood compares to the flooding in 2011.

\subsection{Flood hazard maps}

The flood hazard map is based on the scenario of $15 \operatorname{Tr} 12 \mathrm{H}$ which is in similar manner to 2011 flood occurring at downstream areas of the pilot catchment as shown in Fig. 4. The flood hazard ratings were classified into four levels of flood severities: low, moderate, significant and extreme. The four levels of classification were established based on potential flash flood hazard to people as a function of water depth and velocity (DEFRA, 2006). The key parameters needed to calculate the flood hazard rating was done by using MEADFLOW.

\section{Conclusions}

This paper presents the framework for flash flood hazard mapping in a small ungauged catchment as an example. In tropical countries, such as those in Southeast Asia, intensive guidelines for mapping flash flood hazard are needed. For the creation of flash flood scenarios, our analysis is based on regional frequency analysis. In the regional frequency analysis of rainfall events, L-moments approach is a practical and ro- 
Table 1. Statistical indices indicating performance of the PANTA RHEI model

\begin{tabular}{cccc|ccc}
\hline \multirow{2}{*}{ Discharge stations } & \multicolumn{3}{c|}{ Calibration (26-30 June 2011) } & \multicolumn{3}{|c}{ Validation (17 July-11 August 2008) } \\
& EI & $R^{2}$ & RPE (\%) & EI & $R^{2}$ & RPE (\%) \\
\hline N.65 & 0.78 & 0.91 & 0.18 & 0.77 & 0.82 & -4.71 \\
N.64 & 0.95 & 0.96 & 0.04 & 0.83 & 0.87 & 6.60 \\
N.1 & 0.80 & 0.84 & -0.95 & 0.86 & 0.87 & 3.41 \\
\hline
\end{tabular}

bust tool for identifying the best frequency distribution of a region.

PANTA RHEI was employed to the parent watershed of the ungauged catchment. The capability of PANTA RHEI for producing extreme flood events reasonably performs when subdaily rainfall series are input.

To produce flash flood hazard maps at the ungauged catchment, simulated results from PANTA RHEI were integrated with MEADFLOW. Outcomes from MEADFLOW may vary with response to roughness coefficients. Thus, high flood marks and information from eyewitness are necessary for estimating the coefficients.

Using the presented framework, various flash flood hazard maps based on different rainfall scenarios can be evaluated. This information is considered to be useful in the context of flood protection and management.

Acknowledgements. The present research is financially supported by German Academic Exchange Service (DAAD) (funding programme number 57076385). The authors would like to acknowledge the Leichtweiss Institute for Hydraulic Engineering and Water Resources (LWI) and the Ingenieure für Wasser, Umwelt und Datenverarbeitung GmbH (IWUD) for technical support. The authors would like to express their appreciation to the Royal Irrigation Department (RID), Thai Meteorological Department (TMD), Department of Water Resources (DWR) and Land Development Department (LDD) for providing information and datasets.

\section{References}

Braud, I., Roux, H., Anquetin, S., Maubourguet, M.-M., Manus, C., Viallet, P., and Dartus, D.: The use of distributed hydrological models for the Gard 2002 flash flood event: Analysis of associated hydrological processes, J. Hydrol., 394, 162-181, doi:10.1016/j.jhydrol.2010.03.033, 2010.

Chow, V. T.: Open-channel hydraulics, McGraw-Hill Kogakusha Ltd, Tokyo, 1959.

Chow, V. T., Maidment, D. R., and Mays, L. W.: Applied hydrology, McGraw-Hill, New York, 1988.
Collier, C. G.: Flash flood forecasting: What are the limits of predictability?, Q. J. Roy. Meteor. Soc., 133, 3-23, doi:10.1002/qj.29, 2007.

DEFRA: Flood Risks to People: Phase 2, FD2321/TR2 Guidance Document, DEFRA/Environment Agency, London, 2006.

DMR: Landslides risk maps at community levels, Nan provice (in Thai), Department of Mineral Resources (DMR), Bangkok, 2011.

Förster, K., Meon, G., Marke, T., and Strasser, U.: Effect of meteorological forcing and snow model complexity on hydrological simulations in the Sieber catchment (Harz Mountains, Germany), Hydrol. Earth Syst. Sci., 18, 4703-4720, doi:10.5194/hess-184703-2014, 2014.

Grubbs, F. E.: Procedures for Detecting Outlying Observations in Samples, Technometrics, 11, 1-22, 1969.

Hosking, J. and Wallis, J. R.: Regional frequency analysis: An approach based on L-moments, Cambridge University Press, Cambridge and New York, 1997.

Jonkman, S. N. and Vrijling, J. K.: Loss of life due to floods, Journal of Flood Risk Management, 1, 43-56, doi:10.1111/j.1753318X.2008.00006.x, 2008.

Marchi, L., Borga, M., Preciso, E., and Gaume, E.: Characterisation of selected extreme flash floods in Europe and implications for flood risk management, J. Hydrol., 394, 118-133, doi:10.1016/j.jhydrol.2010.07.017, 2010.

Ogden, F. L., Sharif, H. O., Senarath, S., Smith, J. A., Baeck, M. L., and Richardson, J. R.: Hydrologic analysis of the Fort Collins, Colorado, flash flood of 1997, J. Hydrol., 228, 82-100, doi:10.1016/S0022-1694(00)00146-3, 2000.

Reed, S., Schaake, J., and Zhang, Z.: A distributed hydrologic model and threshold frequency-based method for flash flood forecasting at ungauged locations, J. Hydrol., 337, 402-420, doi:10.1016/j.jhydrol.2007.02.015, 2007.

Rulli, M. C. and Rosso, R.: An integrated simulation method for flash-flood risk assessment: 1. Frequency predictions in the Bisagno River by combining stochastic and deterministic methods, Hydrol. Earth Syst. Sci., 6, 267-284, doi:10.5194/hess-6-2672002, 2002.

Sarhadi, A., Soltani, S., and Modarres, R.: Probabilistic flood inundation mapping of ungauged rivers: Linking GIS techniques and frequency analysis, J. Hydrol., 458-459, 68-86, doi:10.1016/j.jhydrol.2012.06.039, 2012. 